\title{
Gallic Acid Production with Mouldy Polyurethane Particles Obtained from Solid State Culture of Aspergillus niger GH1
}

\author{
Marco Mata-Gómez ${ }^{1,3}$ - Solange I. Mussatto ${ }^{2}$. \\ Raul Rodríguez ${ }^{1}$ - Jose A. Teixeira ${ }^{3}$ Jose L. Martinez ${ }^{1}$. \\ Ayerim Hernandez ${ }^{1} \cdot$ Cristóbal N. Aguilar ${ }^{1}$
}

Received: 15 August 2014 / Accepted: 21 April 2015 /

Published online: 29 April 2015

(C) Springer Science+Business Media New York 2015

\begin{abstract}
Gallic acid production in a batch bioreactor was evaluated using as catalytic material the mouldy polyurethane solids (MPS) obtained from a solid-state fermentation (SSF) bioprocess carried out for tannase production by Aspergillus niger $\mathrm{GH} 1$ on polyurethane foam powder (PUF) with $5 \%(v / w)$ of tannic acid as inducer. Fungal biomass, tannic acid consumption and tannase production were kinetically monitored. SSF was stopped when tannase activity reached its maximum level. Effects of washing with distilled water and drying on the tannase activity of MPS were determined. Better results were obtained with dried and washed MPS retaining $84 \%$ of the tannase activity. Maximum tannase activity produced through SSF after $24 \mathrm{~h}$ of incubation was equivalent to $130 \mathrm{U} / \mathrm{gS}$ with a specific activity of $36 \mathrm{U} / \mathrm{mg}$. The methylgallate was hydrolysed (45\%) in an easy, cheap and fast bioprocess (30 min). Kinetic parameters of tannase self-immobilized on polyurethane particles were calculated to be $5 \mathrm{mM}$ and $04.1 \times 10^{-2} \mathrm{mM} / \mathrm{min}$ for $K_{\mathrm{M}}$ and $V_{\max }$, respectively. Results demonstrated that the MPS, with tannase activity, can be successfully used for the production of the antioxidant gallic acid from methyl-gallate substrate. Direct use of PMS to produce gallic acid can be advantageous as no previous extraction of enzyme is required, thus reducing production costs.
\end{abstract}

Keywords Tannase $\cdot$ Gallic acid $\cdot$ Methyl gallate $\cdot$ Mouldy polyurethane solids $\cdot$ State solid fermentation

Cristóbal N. Aguilar

cristobal.aguilar@uadec.edu.mx

1 Department of Food Research (DIA-UAdeC). School of Chemistry, Universidad Autónoma de Coahuila, Saltillo 25000 Coahuila, Mexico

2 Department of Biotechnology, Delft University of Technology, Julianalaan 67, 2628 BC Delft, The Netherlands

3 IBB - Institute for Biotechnology and Bioengineering, Centre of Biological Engineering, University of Minho, Campus de Gualtar, 4710-057 Braga, Portugal 


\section{Introduction}

Tannin acyl hydrolase (tannase, EC: 3.1.1.20) is an inducible enzyme that catalyses the breakdown of hydrolysable tannins or gallic acid esters [1,2]. Tannase can be produced in presence of tannic acid by microorganisms like bacteria, yeasts and fungi, being the latter the predominant producers [3]. Tannase is extensively used in the food, feed, beverage, brewing, pharmaceutical and chemical industries [4]. The major commercial applications of tannase are the manufacture of instant tea and the production of gallic acid [5].

3,4,5-Trihydroxy benzoic acid (gallic acid) is a phenolic compound with important industrial applications including the manufacture of trimetroprim, an antibacterial agent $[2,6,7]$. It is also used in the enzymatic synthesis of gallic acid esters, e.g. propyl gallate, which is mainly used to prevent antioxidation of fats and oils, as well as beverages [7, 8].

The traditional method for gallic acid production is by chemical (using acid or alkali solutions) or enzymatic hydrolysis (with tannases) of hydrolysable tannins obtained from plants $[9,10]$. Traditionally, microbial tannases are produced by either submerged fermentation $(\mathrm{SmF})$ or solid-state fermentation (SSF). Then culture broths or crude extracts can be concentrated and used directly as source of tannase or purified and used either as free or as immobilized biocatalyst. For industrial application, the immobilization of the enzymes on solid support offers several advantages, including repeated use of the enzyme, easy separation of product, improvement of enzyme stability and continuous operation in packed-bead reactors [11]; however, this kind of system requires the production, recuperation, purification and immobilization of enzyme, which increase the cost.

In SSF systems, the organism grows on particles of solid organic or inert materials, with a minimum of free water in the spaces between the particles. As fungi normally excrete their enzymes when growing in solids media, the particles of fermented solid, referred here as mouldy polyurethane solids (PMS), can act as a support for the tannase, without the need of a previous extraction step $[12,13]$. In this study, we report a novel approach for production of gallic acid from hydrolysis of methyl gallate in a batch bioreactor by using MPS containing Aspergillus niger GH1 tannase self-immobilized during the SSF process.

\section{Materials and Methods}

\section{Microorganism and Culture Medium}

The microorganism used for tannase production, A. niger GH1 strain, belongs to Micoteca of DIA-UAdeC, Food Research Department, Universidad Autónoma de Coahuila, Mexico. To prepare the inoculum, the spores were propagated on mycological agar medium and incubated at $30{ }^{\circ} \mathrm{C}$ for 5 days. Culture medium for the tannase production included $(\mathrm{g} / \mathrm{L}) \mathrm{KH}_{2} \mathrm{PO}_{4}(8.76)$, $\left(\mathrm{NH}_{4}\right)_{2} \mathrm{SO}_{4}$ (17.52), $\mathrm{MgSO}_{4} .7 \mathrm{H}_{2} \mathrm{O}$ (1.76), $\mathrm{CaCl}_{2} .7 \mathrm{H} 2 \mathrm{O}(0.176), \mathrm{MnCl}_{2} .6 \mathrm{H}_{2} \mathrm{O}$ (0.036), $\mathrm{NaMoO}_{4} \cdot 2 \mathrm{H}_{2} \mathrm{O}(0.016), \mathrm{FeSO}_{4} \cdot 7 \mathrm{H}_{2} \mathrm{O}(0.024)$ and tannic acid $(50 \mathrm{~g} / \mathrm{L})$ as sole carbon source. The final $\mathrm{pH}$ was adjusted to 5.5 by adding $0.1 \mathrm{~N} \mathrm{NaOH}$.

\section{Tannase Production by Solid-State Fermentation}

Tannase production was carried out by SSF in 250-mL Erlenmeyer flasks containing $3 \mathrm{~g}$ of pulverized polyurethane foam (PUF) as support and $7 \mathrm{~mL}$ of culture medium $(5 \%$ tannic 
acid), previously inoculated with $2 \times 10^{7}$ spores per gramme of PUF [14]. The final moisture content of the medium was $70 \%(w / w)$. The flasks were incubated at $30{ }^{\circ} \mathrm{C}$ per $48 \mathrm{~h}$. Triplicates were processed for each treatment at each sampling time $(0,12,24,36$ and $48 \mathrm{~h})$.

\section{Analytical Methods}

Kinetic growth of $A$. niger GH1 was determined by the method reported by Aguilar et al., [1]; tannic acid consumption was followed by estimating the hydrolysable tannins using the method of Folin-Ciocalteu according the reported by Makkar et al. [15]; after proper time of fermentation, the enzyme was recovered by addition of $20 \mathrm{~mL}$ of $10 \mathrm{mM}$ acetate buffer at $\mathrm{pH} 5$ to each flask and then it was shaken for $20 \mathrm{~min}$ at $180 \mathrm{rpm}$. The suspension was filtered through cheesecloth to remove the solid particle. The extract was used to determinate the tannase activity and the total protein content. Tannase activity was evaluated according to the HPLC method reported previously by our group [16]. The tannase activity from SSF bioprocess was expressed in two forms. Volumetric activity $(\mathrm{U} / \mathrm{gS})$ was referred to the enzymatic crude extracts obtained from the fermentation. Specific activity $(\mathrm{U} / \mathrm{mg})$ was referred as the units per milligramme of protein. One unit of tannase activity (U) was defined as the amount of enzyme required to release one micromoles of gallic acid per min per gramme of support under standard reaction conditions. Protein content was spectrophotometrically quantified [17].

\section{Preparation of MPS After Fermentation Process}

The MPS containing tannase activity were obtained after $24 \mathrm{~h}$ of fermentation following the procedure described above. MPS were washed with distilled water, packed into a glass column and dried by applying an air current with a flow of $500 \mathrm{~mL} / \mathrm{min}$. After this procedure, the MPS were directly added to the reaction medium for methyl gallate hydrolysis. It is important to note that the effects of washing with distilled water and drying on the tannase activity of MPS were determined by using unwashed dried MPS as a control.

\section{Hydrolysis of Methyl Gallate Using MPS Containing Tannase}

The catalysis was carried out by adding $500 \mathrm{mg}$ of MPS with tannase activity $(0.5 \%$ moisture content) to the reaction mixture contained in 125-mL Erlenmeyer flasks. Mixture reaction consisted of $50 \mathrm{~mL}$ of $5 \mathrm{mM}$ methyl gallate prepared in $5 \mathrm{mM}$ citrate buffer at $\mathrm{pH} 5$. During catalysis, the temperature was kept at $30{ }^{\circ} \mathrm{C}$ and the flasks were shaken at $140 \mathrm{rpm}$. Reaction samples were taken to follow the hydrolysis of substrate, and the formation of product (gallic acid and remaining methyl gallate). The conversion degree was defined as the ratio (M) obtained of released gallic acid per the initial concentration of methyl gallate per $100 \%$. Also, tannase activity was evaluated according to the HPLC method reported previously by our group [16]. For the methyl gallate hydrolysis, the activity tannase (U) of MPS was expressed in units per gramme of dry solids (U/gDS).

\section{Kinetic Parameters of Self-Immobilized Tannase}

Kinetic parameters $K_{\mathrm{M}}$ and $V_{\max }$ of the tannase present in MPS were estimated by determining the initial reaction rate of tannase at various concentrations of methyl gallate (1-9 mM). Kinetic parameters were obtained from the Lineweaver-Burk plot and then were recalculated 
by solving the Michaelis-Menten equation using the Solver module of the Microsoft Excel 2015. Hydrolysis of methyl gallate and formation of gallic acid were analysed by HPLC. The equipment consisted of an HPLC pump solvent delivery system coupled to a Perkin Elmer Series 200 UV visible detector. A chromatography interface series 600 LINK was used to process the data. Separation of the compounds was performed by using an ODS $(150 \times 4.6 \mathrm{~mm}$ $5 \mu \mathrm{m}$, Phenomenex) analytical column and an ODS $(4.6 \mathrm{~mm} \times 5 \mu \mathrm{m})$ pre-column. Elution of the sample was performed by applying an isocratic flow $(1 \mathrm{~mL} / \mathrm{min})$ of a mobile phase consisting of $35 \%$ methanol, $5 \%$ acetic acid and $60 \%$ distilled water. The compounds were monitored at $254 \mathrm{~nm}$. Gallic acid and methyl gallate were used as standards,

\section{Statistical Analysis}

The results were evaluated in triplicate using an experimental design with factorial fix. The statistical analysis was performed using the Statistical Program Infostat (Córdoba, Argentina).

\section{Results and Discussion}

\section{Tannase Production}

Tannase production by $A$. niger GH1 was evaluated in SSF using polyurethane foam powder as support. Values of $a_{\mathrm{w}}$ and moisture content indicated a good performance of the bioprocess (Fig. 1), in which A. niger GH1 grew rapidly consuming almost all the tannic acid (Fig. 2). Figure 3 shows the production profiles of volumetric and specific tannase activities. Secretion of enzyme started at after $12 \mathrm{~h}$ of fermentation reaching the maximal activity at $24 \mathrm{~h}$ of culture process with high values of $130 \mathrm{U} / \mathrm{gS}$ and $36 \mathrm{U} / \mathrm{mg}$ for volumetric and specific activities, respectively. Decrements of tannase activity after $48 \mathrm{~h}$ of culture are due to the proteolyitic action as reported previously by our group [18]. Kumar [19] studied the tannase production by

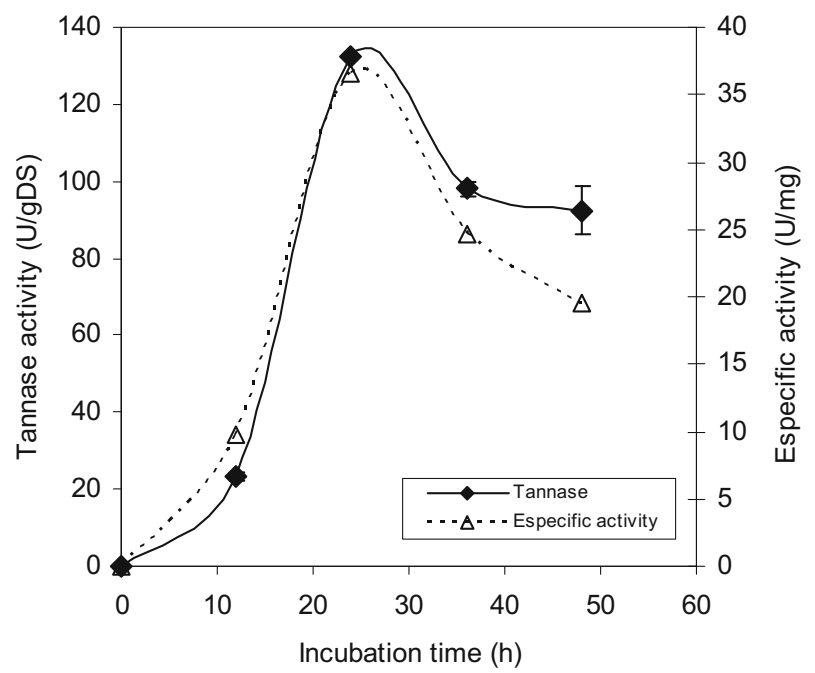

Fig. 1 Production profiles of volumetric and specific tannase activities by A. niger GH 1 in SSF using polyurethane foam powder as support and $5 \%$ tannic acid as inducer 


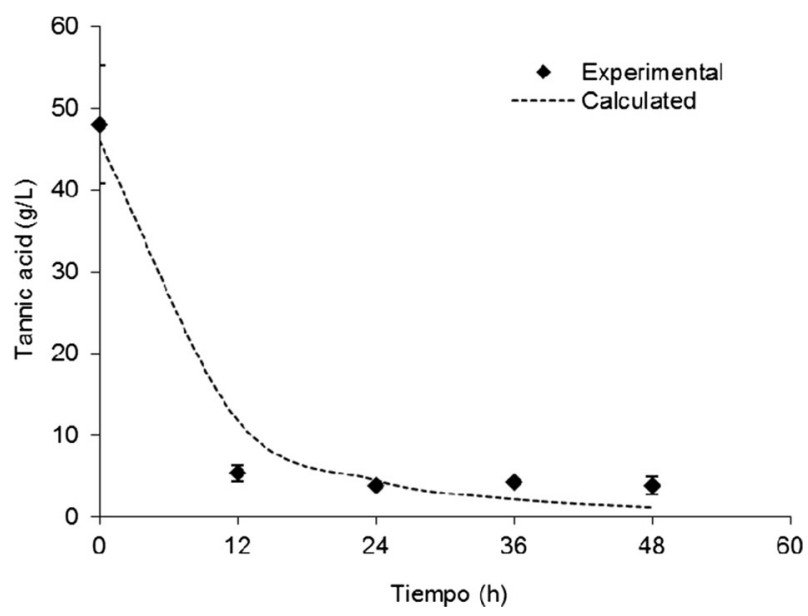

Fig. 2 Tannic acid consumption during the growth of $A$. niger GH1 in SSF

A. ruber in SSF using jamum leaves reporting a maximum activity value at $96 \mathrm{~h}$ of fermentation with an activity of $64 \mathrm{U} / \mathrm{gS}$ lower than the activity level reported in this study.

\section{Production of MPS with Tannase Activity}

Once the culture time at which maximum tannase activity is achieved is determined, the next step was the production of MPS. For this, several column bioreactors were again prepared for SSF and the bioprocess was stopped at $24 \mathrm{~h}$ of culture time, the MPS were collected, washed with distilled water and dehydrated as described in the "Materials and Methods" section. Tannase activity of MPS was assayed before (control) and after washing.

The next step was to determine the tannase activity of fermented solids (Fig. 3). After $24 \mathrm{~h}$ of incubation, the fermented solids containing tannase presented an activity of $130 \mathrm{U} / \mathrm{gSS}$.

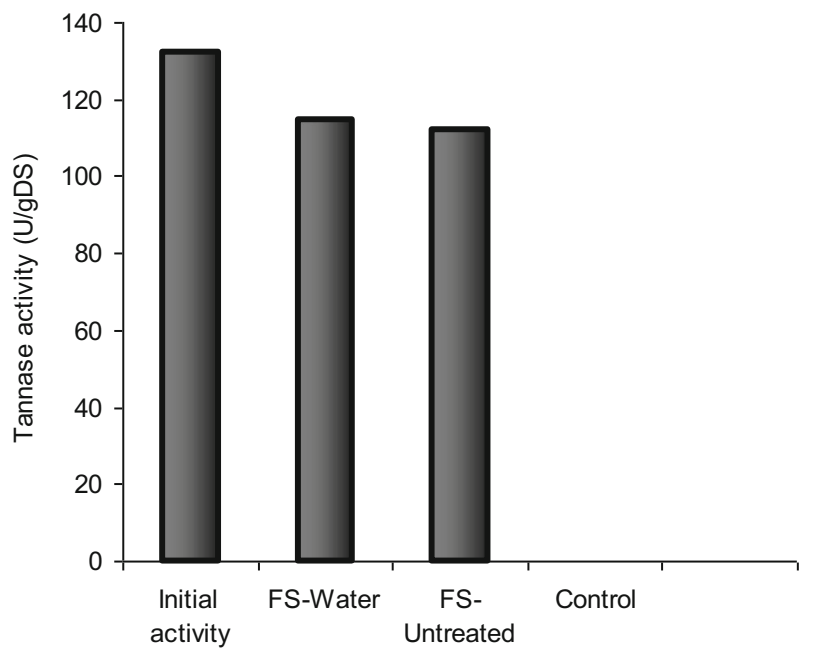

Fig. 3 Tannase activity of fermented solids using methyl gallate $(5 \mathrm{mM})$ as substrate at $30{ }^{\circ} \mathrm{C}$ 
This activity decreased after the drying process up to 114 and $112 \mathrm{U} / \mathrm{gSS}$ for fermented solids treated with water and without water, respectively; this decrement correspond to a residual activity of $84 \%$. Drying process had an effect on the enzymatic activty, therefore evaluation of other drying and freeze drying is necessary.

\section{Hydrolysis of Methyl Gallate Using MPS}

Once the enzyme activity of MPS was determined, the hydrolysis of methyl gallate was conducted in batch reactor. Figure 4 shows the hydrolysis of methyl gallate using MPS with self-immobilized tannase. It can be seen that hydrolysis of the substrate started after $5 \mathrm{~min}$ of reaction. The maximum rate of hydrolysis, achieved after 30 min of reaction, was 45 and $35 \%$ for MPS treated with water and without water, respectively. It should be noted that there was no hydrolysis of methyl gallate with the control as shown in Fig. 4. This suggests the selfimmobilized tannase is responsible for the catalysis of the substrate.

Figure 5 shows the molar conversion percentage, which is the relation between the concentration of gallic acid formed and the initial concentration of methyl gallate. It is observed that the initial reaction rate increases rapidly during the first minutes until reaching an equilibrium after $25 \mathrm{~min}$ of reaction. The maximum percentage of molar conversion, achieved under these reaction conditions, was approximately $8 \%$. These results suggest that optimization of reaction parameters is needed to increase the yield. Despite this low yield, it should be emphasized that the self-immobilized tannase on polyurethane foam MPS was able to perform hydrolysis of methyl gallate. In the literature, there are some reports of the use of similar systems but for other purposes. Fernándes et al., [13] reported the production of lipase in solid-state fermentation and the biocatalysis of esterification reaction and transesterification through the direct addition of lyophilized fermented solid to an organic reaction medium. Other work reported in literature is related to the synthesis of propyl gallate in organic solvents

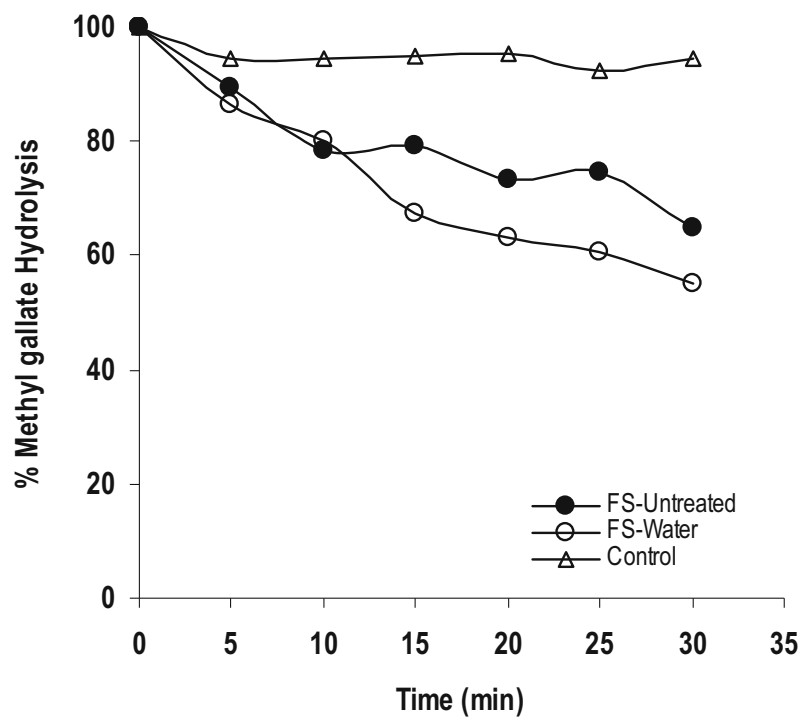

Fig. 4 Methyl gallate hydrolysis using fermented solids with tannase activity 


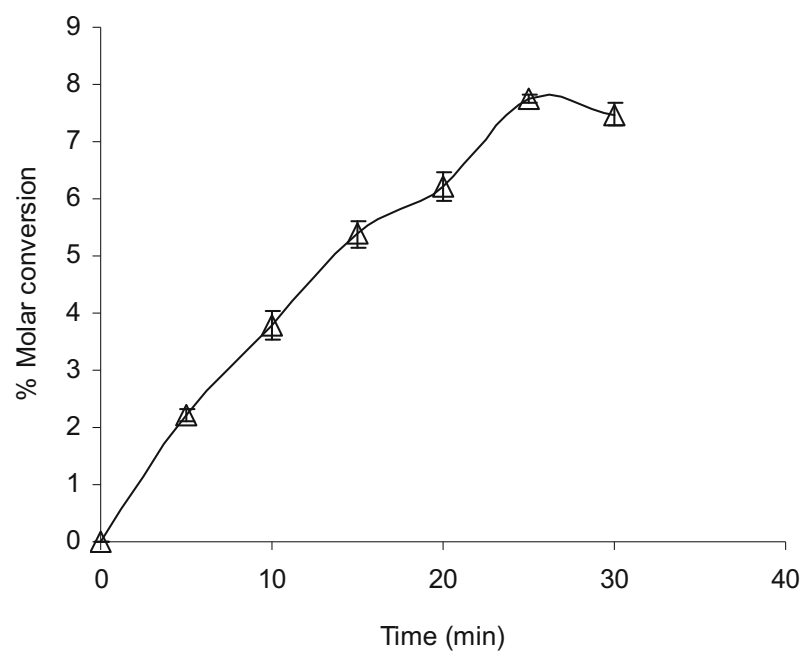

Fig. 5 Molar conversion percentage of methyl gallate hydrolysis reaction

medium using tannase linked to A. niger mycelium as catalyst [3]. This work demonstrated that the tannase enzyme present in the mycelium of the fungus was able to carry out the propyl gallate synthesis from gallic acid and propanol. This can support the idea, in our study, that the tannase not only may be linked to the mycelium but also may be present on the support, polyurethane foam. However, it is necessary to conduct more studies to demonstrate exact location of enzyme in such systems.

It is noteworthy to mention that the novel approach presented here allows the direct use of MPS with tannase activity to the reaction medium resulting in hydrolysis of methyl gallate. This is advantageous as establishment of downstream processing strategies to recover and purify the enzyme, as normally performed, is not required. This in turn, results in lower production costs. Nonetheless, it has to be mentioned that optimization of the catalysts should be conducted.

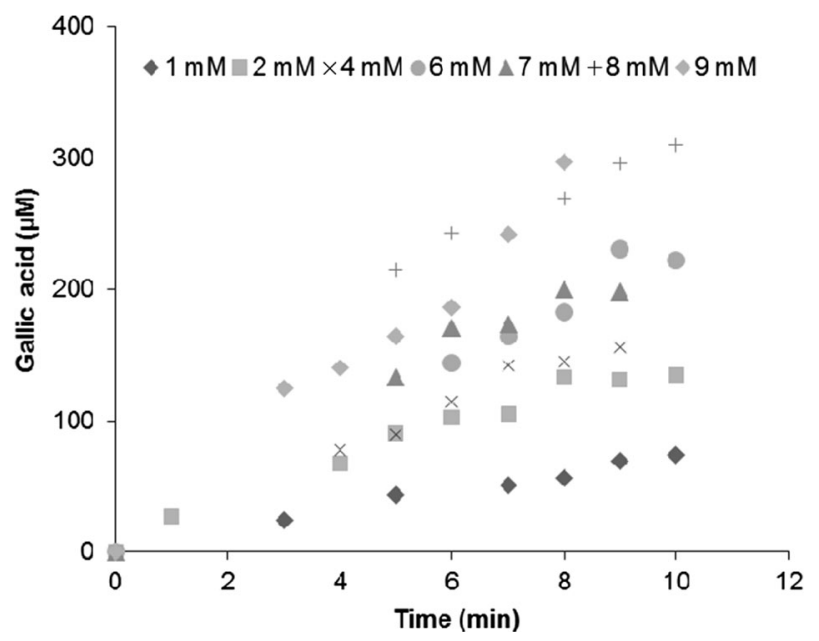

Fig. 6 Effect of concentration of methyl gallate on the initial rate of self-immobilized tannase 


\section{Effect of Substrate Concentration on the Initial Reaction Rate of Tannase: Determination of Kinetic Parameter}

Effect of concentration of methyl gallate on initial rate of tannase was studied by varying the concentration of the substrate. As can be seen in Fig. 6, initial reaction rate increases as the methyl gallate concentration increases. Maximum initial reaction rate was achieved with a concentration of $9 \mathrm{mM}$ methyl gallate.

Kinetic parameters $K_{\mathrm{M}}$ and $V_{\max }$ for self-immobilized tannase on MPS were determined using methyl gallate as substrate. Graphic method of Lineweaver-Burk and Michaelis-Menten plot are presented in Fig. 7. Values of $4.9 \mathrm{mM}$ and $4.310^{-2} \mathrm{mM} / \mathrm{min}$ were obtained for $K_{\mathrm{M}}$ and $V_{\max }$, respectively, using the Lineweaver-Burk method. The $K_{\mathrm{M}}$ and $V_{\max }$ values obtained by the method of Lineweaver-Burk were further recalculated using the Michaelis-Menten model (Fig. 8) by employing the Solver tool of Microsoft Excel software. These resulting values were $5 \mathrm{mM}$ and $4.1 \times 10^{-2} \mathrm{mM} / \mathrm{min}$ for $K_{\mathrm{M}}$ and $V_{\max }$, respectively, which are similar to those obtained using the Lineweaver-Burk method. Sharma et al. [20] reported a $K_{\mathrm{M}}$ value of $14 \mathrm{mM}$
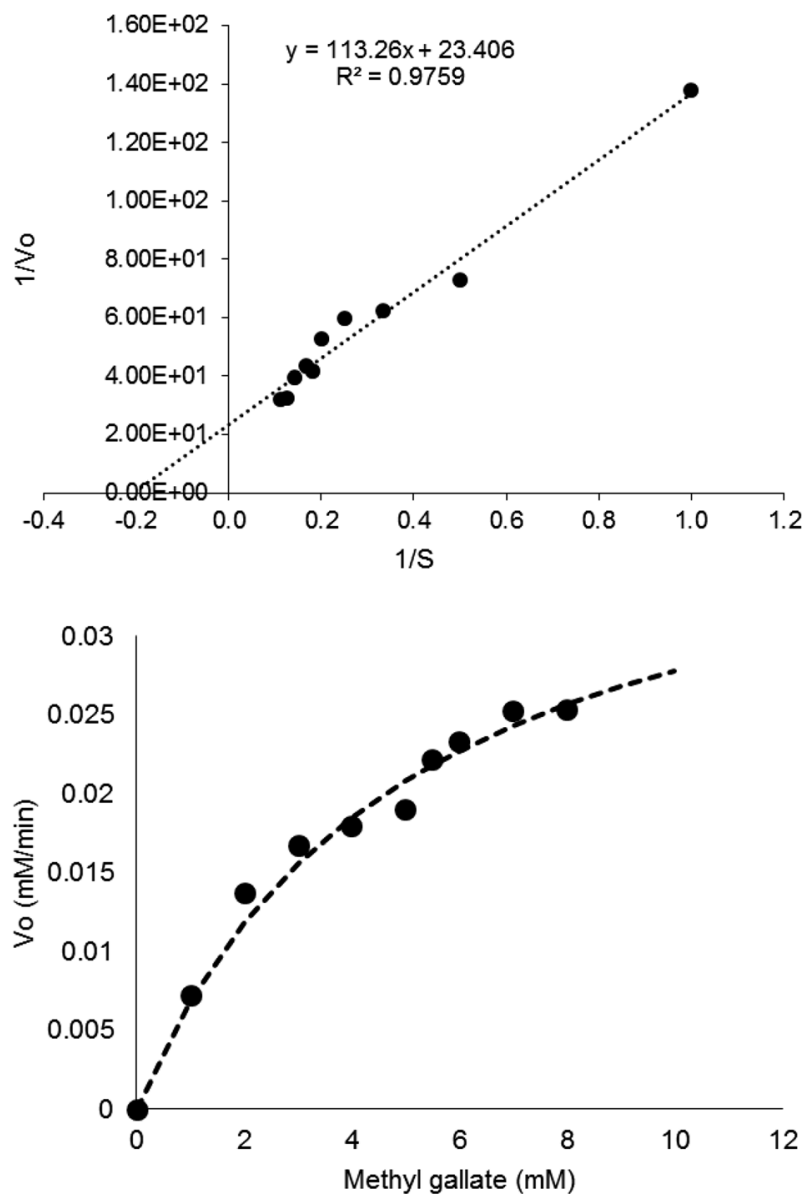

Fig. 7 Graphic method of Lineweaver-Burk (upper) and Michaelis-Menten plot (lower) describing the kinetic behaviour of self-immobilized tannase on mouldy polyurethane solids 
for an immobilized tannase from Penicillium variable using as substrate methyl gallate. This value is 2.8 times higher than that of the $K_{\mathrm{M}}$ reported in this paper, indicating that the tannase self-immobilized on polyurethane foam has a higher affinity for methyl gallate. On the other hand, it should be mentioned that the $K_{\mathrm{M}}$ value of the self-immobilized tannase in MPS is higher than that of the value reported for a non-immobilized tannase, which is $0.2 \mathrm{mM}$ [21]. This suggests that the tannase present in the MPS has lower affinity for the substrate than nonimmobilized tannases. This may due to the fact that the support itself may act as a hindrance avoiding that the catalytic site of the enzyme interacts with the substrate. This could explain why the $K_{\mathrm{M}}$ value of MPS is higher than that of non-immobilized tannases. In fact, the tannase, produced by the same strain studied here, exhibited a $K_{\mathrm{M}}$ value of $1.82 \mathrm{mM}$ upon methyl gallate when it was used in a free form [22]. This suggests that the polyurethane support can affect the interaction between substrate and the enzyme. It can be seen that the initial reaction rate increases as the concentration of methyl gallate increases until the equilibrium after a concentration of $7 \mathrm{mM}$ methyl gallate. It is evident that a substrate inhibition is not observed; it would be important to increase the concentration range of methyl gallate to check if an inhibitory effect of substrate is possible. Inhibition by-product, gallic acid, should also be studied.

\section{Conclusion}

Results show that the $A$. niger GH1 tannase can be produced in solid state fermentation using polyurethane foam as support, and tannic acid as a sole carbon source, energy and inductor plus immobilized tannase in polyurethane produced during A. niger GH1 growth. Fermented solids produced during fermentation were able to catalyse the hydrolysis of methyl gallate reaching an hydrolysis up to $45 \%$. Low yields of gallic acid suggest optimization of the reaction parameters. Moreover, the novel system presented here-which involves the direct use of fermented solids containing tannase activity into the reaction medium-present an important aspect that can be advantageous. It allows to prevent the establishment of recovery steps, purification and immobilization of the enzyme, which can significantly reduce the costs of biocatalysis with tannases. Such systems are sought as alternatives to other processes in order to reduce production costs, but need to be explored in more detail.

Acknowledgments Authors thank the National Council for Science and Technology (CONACYT-Mexico) for the financial support. The present work was performed as part of a cooperative agreement between DIAUniversidad Autónoma de Coahuila (Mexico) and IBB-Universidade do Minho (Portugal) within a specific training stay undertaken at the DEB-UM. Part of the research was funded by a project SEP-CONACYT-CB-2011.

\section{References}

1. Aguilar, C. N., Favela, C., Augur, C., \& Viniegra-González, G. (2001). Production of tannase by Aspergillus niger Aa-20 in submerged and solid-state fermentation: influence of glucose and tannic acid. Journal of Industrial Microbiology and Biotechnology, 26, 296-302.

2. Lekha, P., \& Lonsane, B. (1997). Production and application of tannin acyl hydrolase: state of the art. Advances in Applied Microbiology, 44, 215-260.

3. Yu, X.-W., Li, Y.-Q., Zhou, S.-M., \& Zheng, Y.-Y. (2007). Synthesis of propyl gallate by mycelium-bound tannase from Aspergillus niger in organic solvent. World Journal of Microbiology and Biotechnology, 23, 1091-1098. 
4. Sabu, A., Shegal Kiran, G., \& Pandey, A. (2005). Purification and characterization of tannin acyl hydrolase from Aspergillus niger ATCC 16620. Food Technology and Biotechnology, 43, 133-138.

5. Coggon, P. G. N., \& Sanderson, G. W. (1975). UK Patent, 1(380), 135.

6. Kar, B., Banerjee, R., \& Bhattacharyya, B. C. (1999). Microbial production of gallic acid by modified solid state fermentation. Journal of Industrial Microbiology and Biotechnology, 23, 173-177.

7. Treviño-Cueto, B., Luis, M., Contreras-Esquivel, J. C., Rodríguez, R., Aguilera, A., \& Aguilar, C. N. (2007). Gallic acid and tannase accumulation using fungal solid state culture of a tannin-rich desert plant (Larrea tridentata Cov.). Bioresource Technology, 98, 721-724.

8. Hadi, T.A. (1993). $\mathrm{PhD}$ thesis, Indian Institute of Technology, Kharagpur, IN.

9. Chen, S. C., \& Chung, K. T. (2000). Mutagenicity and antimutagenicity studies of tannic acid and its related compounds. Food and Chemical Toxicology, 38, 1-5.

10. Garro, J. M., \& Jollez, P. (1997). Canadian Patents, 215, 251.

11. Abdel-Naby, M. A., Sherif, A. A., El-Tanash, A. B., \& Mankarios, A. T. (1999). Immobilization of Aspergillus oryzae tannase and properties of the immobilized enzyme. Journal of Applied Microbiology, $87,108-114$.

12. Nagy, V., Toke, E. R., Keong, L. C., Szatzker, G., Ibrahim, D., Omar, I. C., Szakacs, G., \& Poppe, L. (2006). Kinetic resolutions with novel, highly enantioselective fungal lipases produced by solid state fermentation. Journal of Molecular Catalysis B: Enzymatic, 39, 141-148.

13. Fernandes, M. L. M., Saad, E. B., Meira, J. A., Ramos, L. P., Mitchell, D. A., \& Krieger, N. (2006). Esterification and transesterification reactions catalysed by addition of fermented solids to organic reaction media. Journal of Molecular Catalysis B: Enzymatic, 263, 8-13.

14. Rodriguez-Duran, L. V., Contreras-Esquivel, J. C., Rodriguez, R., Prado-Barragan, L. A., \& Aguilar, C. N. (2011). Optimization of tannase production by Aspergillus niger in solid-state packed-bed bioreactor. Journal of Microbiology and Biotechnology, 21, 960-967.

15. Makkar, H. P. S., Blummel, M., Borowy, N. K., \& Becker, K. (1993). Gravimetric determination of tannins and their correlations with chemical and protein precipitation methods. Journal of the Science of Food and Agriculture, 61, 161-165.

16. Aguilar, C., Augur, C., Viniegra-González, G., \& Favela, E. (1999). A comparison of methods to determine tannin acyl hydrolase activity. Brazilian Archives of Biology and Technology, 42(3), 355-362.

17. Bradford, M. M. (1976). A rapid and sensitive method for the quantitation of microgram quantities of protein utilizing the principle of protein-dye binding. Analytical Biochemistry, 72(1), 248-254.

18. Aguilar, C. N., Favela-Torres, E., Viniegra-González, G., \& Augur, C. (2002). Culture conditions dictate protease and tannase production in submerged and solid-state cultures of Aspergillus nigerAa-20. Applied Biochemistry and Biotechnology, 102-103, 407-414.

19. Kumar, R., Sharma, J., \& Singh, R. (2007). Production of tannase from Aspergillus ruber under solid-state fermentation using jamun (Syzygium cumini) leaves. Microbiological Research, 162, 384-390.

20. Sharma, S., Agarwal, L., \& Saxena, R. K. (2008). Purification, immobilization and characterization of tannase from Penicillium variable. Bioresource Technology, 99, 2544-2551.

21. Sharma, S., Bhat, T. K., \& Dawra, R. K. (1999). Immobilization and characterization of tannase from a metagenomic library and its use for removal of tannins from green tea infusion. World Journal of Microbiology and Biotechnology, 15, 673-677.

22. Ramos, E. L., Mata-Gómez, M. A., Rodríguez-Durán, L. V., Belmares, R. E., Rodríguez-Herrera, R., \& Aguilar, C. N. (2011). Catalytic and thermodynamic properties of a tannase produced by Aspergillus niger GH1 grown on polyurethane foam. Applied Biochemistry and Biotechnology, 165, 1141-1151. 